\title{
Phrenic nerve block caused by interscalene brachial plexus block: breathing effects of different sites of injection
}

\author{
Lars Bergmann ${ }^{* *}$ D, Stefan Martini ${ }^{1}$, Miriam Kesselmeier ${ }^{2}$, Wolf Armbruster ${ }^{3}$, Thomas Notheisen ${ }^{4}$, \\ Michael Adamzik ${ }^{1}$ and Rüdiger Eichholz ${ }^{4}$
}

\begin{abstract}
Background: Interscalene brachial plexus (ISB) block is often associated with phrenic nerve block and diaphragmatic paresis. The goal of our study was to test if the anterior or the posterior ultrasound guided approach of the ISB is associated with a lower incidence of phrenic nerve blocks and impaired lung function.

Methods: This was a prospective, randomized and single-blinded study of 84 patients scheduled for elective shoulder surgery who fullfilled the inclusion and exclusion critereria. Patients were randomized in two groups to receive either the anterior $(n=42)$ or the posterior $(n=42)$ approach for ISB. Clinical data were recorded. In both groups patients received ISB with a total injection volume of $15 \mathrm{ml}$ of ropivacaine $1 \%$. Spirometry was conducted at baseline $\left(T_{0}\right)$ and 30 min $\left(T_{30}\right)$ after accomplishing the block.

Changes in spirometrical variables between $T_{0}$ and $T_{30}$ were investigated by Wilcoxon signed-rank test for each puncture approach. The temporal difference between the posterior and the anterior puncture approach groups were again analyzed by the Wilcoxon-Mann-Whitney test.

Results: The spirometric results showed a significant decrease in vital capacity, forced expiratory volume per second, and maximum nasal inspiratory breathing after the Interscalene brachial plexus block; indicating a phrenic nerve block ( $p<0.001$, Wilcoxon signed-rank). A significant difference in the development of the spirometric parameters between the anterior and the posterior group could not be identified (WilcoxonMann-Whitney test). Despite the changes in spirometry, no cases of dyspnea were reported.

Conclusion: A different site of injection (anterior or posterior) did not show an effect in reducing the cervical block spread of the local anesthetic and the incidence of phrenic nerve blocks during during ultrasound guided Interscalene brachial plexus block. Clinical breathing effects of phrenic nerve blocks are, however, usually well compensated, and subjective dyspnea did not occur in our patients.
\end{abstract}

Trial registration: German Clinical Trials Register (DRKS number 00009908, registered 26 January 2016).

Keywords: Injections site, Interscalene block, Phrenic nerve, Breathing effects

\footnotetext{
* Correspondence: Lars.Bergmann@kk-bochum.de

${ }^{1}$ Klinik für Anästhesiologie, Intensivmedizin und Schmerztherapie,

Knappschaftskrankenhaus Bochum Langendreer, Ruhr-Universität Bochum, In

der Schornau 23-25, 44892 Bochum, Germany

Full list of author information is available at the end of the article
} 


\section{Background}

Over the last 15 years, ultrasound guided peripheral nerve block techniques have grown increasingly popular in regional anesthesia in addition to landmark guided techniques and neurostimulation [1, 2]. The brachial plexus and the phrenic nerve can be depicted quite well sonographically in the interscalene region [3]. Interscalene brachial plexus blocks (ISB) only using nerve stimulation or eliciting paresthesias are associated with a high rate (up to $100 \%$ ) of phrenic nerve blocks [4-6]. Two possible reasons for this are either a $C_{3}, C_{4}$ and $C_{5}$ nerve root block, caused by cranial spread of the blind injection of a high volume of local anesthetic, or a direct phrenic nerve block within the anterior scalene muscle fascia $[7,8]$. Due to unilateral diaphragmatic paresis, the mechanics of breathing can be considerably impaired; thus, patients with impaired pulmonary function are often advised against interscalene blocks [9]. Studies have shown phrenic nerve blocks can be significantly reduced by decreased local anesthetic volumes, lower volumes usually require using ultrasound guided technique $[6,10]$.

The objective of this study is to investigate if the anterior ultrasound guided anterior puncture approach compared to the posterior approach of the $C_{5}, C_{6}, C_{7}$ nerve roots reduces the frequency of unintentional phrenic nerve blocks measured by spirometry. The rationale for the comparison of the anterior versus posterior approach is based on the idea, that anatomically the posterior site of injection has a greater distance to the phrenic nerve than the anterior site. Additionally, using the anterior approach, the local anesthetic can easily spread along the fascia of the anterior scalene muscle and block the phrenic nerve on its course to the chest. Different rates of hemidiaphragmatic paresis could support new recommendations on how to perform ultrasound guided interscalene brachial plexus blocks.

\section{Methods}

This prospective, single-center, randomized, singleblinded, parallel study was conducted in accordance with the ethical principles of the Helsinki Declaration, and was approved by the Ethics Committe oft he Eberhard Karls University in Tuebingen (Germany) (Research Ethics Committee No. 579/2010B01). This study was registered at the German Clinical Trial Register (DRKS number 00009908, registered 26 January 2016). URL: https://drksneu.uniklinik-freiburg.de/drks_web/navigate.do?navigationId=trial.HTML\&TRIAL_ID=DRKS00009908.

A total of 84 patients scheduled for elective shoulder surgery gave written informed consent and were included in this study. The criteria for exclusion were age $<18$ or $>70$ years, ASA status $>$ II, an allergy to the local anesthetic used, psychiatric disorders, and pre-existing lung disease $(\mathrm{GOLD}>\mathrm{II})$ [11]. The spirometric examination and the nerve block were always performed by the same anesthesiologist. A pre-procedural ultrasound scan showing unequivocal identification of patients' $\mathrm{C}_{5}, \mathrm{C}_{6}, \mathrm{C}_{7}$ nerve roots, increasing the likelihood of a well-targeted block, in each patient was also a prerequisite. All data were collected from a questionnaire which was filled out by the investigator.

\section{Sample size calculation and randomization}

A sample size $(2 \times 36$ patients) allows for detecting a between-group mean difference of 0.75 (standardized effect in units of standard normal distribution; a moderate to strong effect using Cohnes classification) with a comparison-wise power of $88 \%$ at a two-sided significance level $\alpha=5 \%$ (planning for Student's t-test). Addressing a potential drop-out rate, we decided to randomize an additional $2 \times 7$ patients (drop-out rate of $\sim 15 \%$ ). A total sample size of $2 \times 42$ patients has $80 \%$ power to detect a between-group mean difference of 0.62 , which is still a relatively large (but likely clinically relevant) effect. The 84 patients were allocated via block randomization with a block size of six to either one of the groups, realized by 84 similar looking and closed envelopes.

\section{Anesthesiologic procedure}

All patients were studied without sedation in order to avoid any interference in the spirometric tests. Venous access and patient monitoring were established (ECG, pulsoximetry and non-invasive blood pressure). ISB was performed exclusively by two staff anesthetist only, both being experts in ultrasound guided procedures.

\section{First spirometric examination}

Following randomization a baseline spirometry measurement (Masterscope PC, Carefusion, Heidelberg, Germany) was performed on patients in the sitting position with the upper part of the body in an upright position. The lung function tests comprised the vital capacity (VC [1]), forced expiratory volume per second $\left(\mathrm{FEV}_{1}[\mathrm{l} / \mathrm{s}]\right)$, and maximum nasal inspiratory breathing maneuver (Sniff PmaxPeak $[\mathrm{kPa}]$ ). The best values (VC, FEV1 and Sniff PmaxPeak) were determined from three repeated measurements.

\section{Anterior approach}

The skin was anesthetized under ultrasound surveillance to ensure that there was no spread of any local anesthetic below the sternocleidomastoid muscle, potentially causing unintended direct phrenic nerve block. Thereafter, we performed an ultrasound guided insertion of a cannula (Stimuplex A, 21 G, B.Braun, Melsungen, Germany) between the anterior scalene muscle and the $\mathrm{C}_{5}, \mathrm{C}_{6}, \mathrm{C}_{7}$ nerve roots. After having positioned the needle tip in front of the $\mathrm{C}_{7}$ nerve root, an injection of $5 \mathrm{ml}$ 
ropivacaine $1 \%$ was administered. The same needle tip position and injection volume was used for both $\mathrm{C}_{6}$ and $\mathrm{C}_{5}$, resulting in a total injection volume of $15 \mathrm{ml}$. In cases where the nerve roots were moved away from the needle tip as a result of the local anesthetic injection, corrections to the needle position were explicitly allowed ensuring direct contact of the local anesthetic to the nerve roots (Fig. 1).

\section{Posterior approach}

The skin was anesthetized under ultrasound surveillance to ensure that there was no spread of any local anesthetic below the sternocleidomastoid muscle, potentially causing unintended direct phrenic nerve block. Thereafter, we performed an ultrasound guided insertion of a cannula (Stimuplex A, 21 G, B.Braun, Melsungen, Germany) between the median scalene muscle and the $\mathrm{C}_{5}, \mathrm{C}_{6}, \mathrm{C}_{7}$ nerve roots. After having positioned the needle tip posteriorly of the $C_{7}$ nerve root, an injection of $5 \mathrm{ml}$ ropivacaine $1 \%$ was administered. The same needle tip position and injection volume was used for both $\mathrm{C}_{6}$ and $\mathrm{C}_{5}$, resulting in a total injection volume of $15 \mathrm{ml}$. In cases where the nerve roots were moved away from the needle tip as a result of the local anesthetic injection, corrections to the needle position were explicitly allowed ensuring direct contact of the local anesthetic to the nerve roots (Fig. 2).

After the ISB was performed, using either approach, a subcutaneous infiltration of $5 \mathrm{ml}$ ropivacaine $1 \%$ administered along the clavicle up to the acromion was done to block the suprascapular nerves in addition to the interscalene brachial plexus.

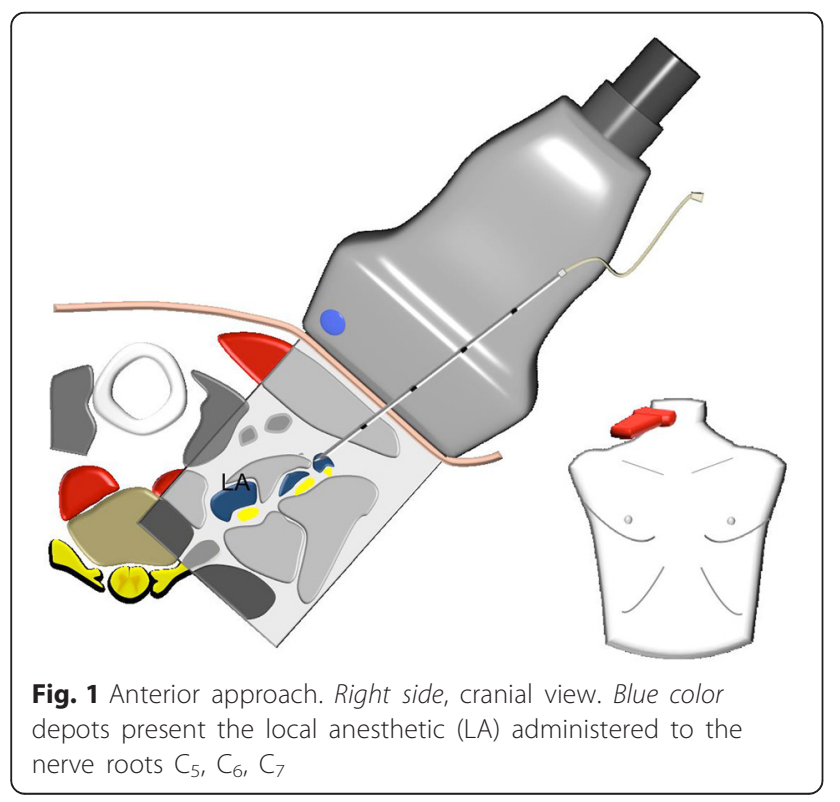

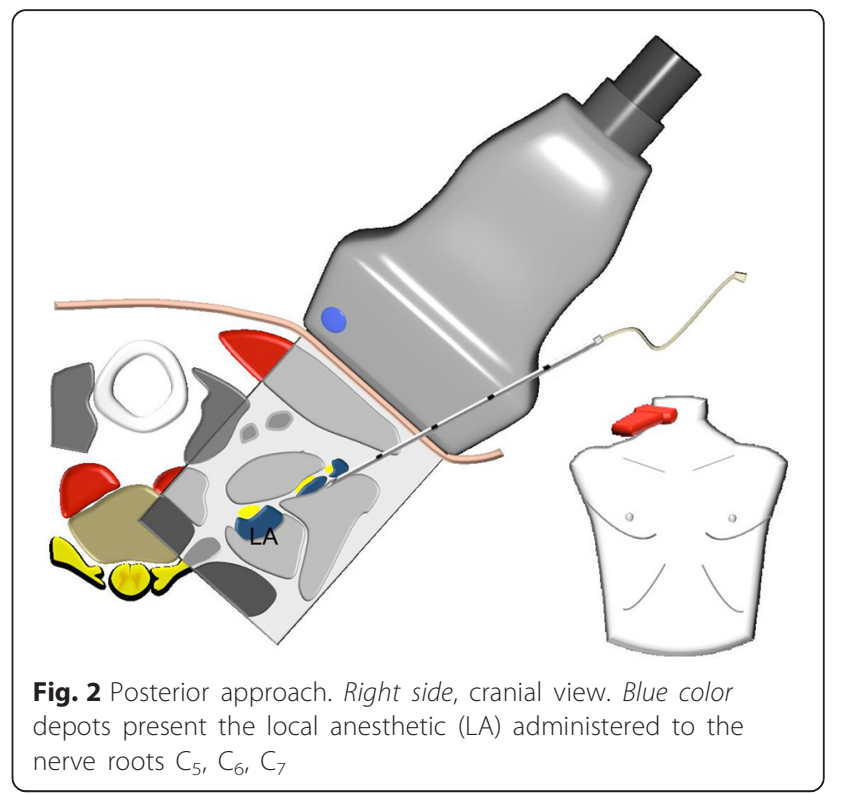

\section{Follow-up spirometric examination}

The second spirometric examination of the patients was carried out $30 \mathrm{~min}$ after implementation of the interscalene block. Patient posture and spirometric tests were identical to the first spirometric examination.

A decrease of the $\mathrm{VC}, \mathrm{FEV}_{1}$ or the Sniff Pmaxpeak by $>20 \%$ following the first baseline spirometry was defined as a criterion for a hemidiaphragmatic paresis [11].

\section{Sedation}

After the follow-up spirometry was completed, all the patients received $0.033 \mathrm{mg} / \mathrm{kg}$ body weight midazolam, $0.067 \mu \mathrm{g} / \mathrm{kg}$ body weight sufentanil, and $0.0133 \mathrm{mg} / \mathrm{kg}$ body weight propofol for sedation. To lower blood pressure, clonidine was administered when necessary up to a maximum dose of $300 \mu \mathrm{g}$ intravenously. All operations were planned without general anesthesia. Subsequently, the unplanned need for general anesthesia was used as a criterion to evaluate the block success rate.

\section{Statistics}

Patients' characteristics were summarized by quartiles in case of quantitative continuous variables or by relative and absolute frequencies in case of count variables. To verify the randomization, we performed explorative comparisons between groups (i.e. the two differing approaches) using Wilcoxon-Mann-Whitney tests for quantitative continuous variables or Fisher's exact tests for count variables; we observed no evidence for baseline differences.

Changes in spirometrical variables between baseline $\left(\mathrm{T}_{0}\right)$ and 30 min later $\left(\mathrm{T}_{30}\right)$ were analyzed by Wilcoxon signed-rank tests for each puncture approach. The temporal difference $\left(\mathrm{D}=\mathrm{T}_{0}-\mathrm{T}_{30}\right)$ between the posterior and 
the anterior puncture approach groups $\left(D_{\text {posterior }}-D_{\text {anterior }}\right)$ were again investigated by Wilcoxon-Mann-Whitney tests. As sensitivity analysis, we additionally compared the posterior and the anterior puncture approach groups at both time points $\left(\mathrm{T}_{0}\right.$ and $\mathrm{T}_{30}$ ) by Wilcoxon-MannWhitney tests. We applied a two-sided significance level $\alpha=5 \%$, did not correct for multiple testing and report two-sided p-values. $95 \%$ confidence intervals $(95 \% \mathrm{CI}$ ) were derived with normal approximation. $95 \% \mathrm{CI}$ for binomial proportions are Clopper-Pearson-Intervals. All analyses were performed using $\mathrm{R}$ version 3.0.2.

\section{Results}

We observed no difference in in patients characteristis and baseline spirometry results between the two ISB approaches (Table 1).

At the time of the second spirometry, all patients except one showed a complete motor block of the upper extremity. One patient from the posterior approach group needed a general anesthetic due to an insufficient nerve block. In all other patients the operation could be performed under regional anesthesia and sedation resulting in a total block success rate of 98.8 \% $(95 \%$ CI: 96.5-100.0\%).

Table 1 Patients' characteristics by puncture approach at baseline

\begin{tabular}{|c|c|c|}
\hline \multirow[t]{2}{*}{ Patient characteristic } & $\begin{array}{l}\text { Anterior puncture } \\
\text { approach }\end{array}$ & $\begin{array}{l}\text { Posterior puncture } \\
\text { approach }\end{array}$ \\
\hline & $N_{\text {total }}=42$ & $N_{\text {total }}=42$ \\
\hline Nfemales (\%) & $12(29 \%)$ & $13(31 \%)$ \\
\hline Median age [years] & 51 & 50 \\
\hline (Q1, Q3) & $(43,56)$ & $(41,56)$ \\
\hline $\begin{array}{l}\text { Median Body Mass Index } \\
{\left[\mathrm{kg} / \mathrm{m}^{2}\right]}\end{array}$ & 26 & 28 \\
\hline (Q1, Q3) & $(25,29)$ & $(25,31)$ \\
\hline \multicolumn{3}{|l|}{$\mathrm{N}_{\text {surgical procedure }}(\%)$} \\
\hline $\begin{array}{l}\text { Arthroskopic labrum } \\
\text { refixation }\end{array}$ & $23(55)$ & $22(52)$ \\
\hline $\begin{array}{l}\text { Open labrum } \\
\text { refixation }\end{array}$ & $13(31)$ & $13(31)$ \\
\hline Other & $6(14)$ & $7(17)$ \\
\hline \multicolumn{3}{|l|}{$\mathrm{N}_{\text {diagnosis }}(\%)$} \\
\hline Tendinosis calcacera & $14(33)$ & $18(43)$ \\
\hline $\begin{array}{l}\text { Lesion of the rotator } \\
\text { cuff }\end{array}$ & $16(38)$ & $13(31)$ \\
\hline Bankart lesion & $10(24)$ & $6(14)$ \\
\hline Other & $2(5)$ & $5(12)$ \\
\hline \multicolumn{3}{|c|}{ Median spirometry variables at baseline (Q1, Q3) } \\
\hline VC $[1]$ & $5.09(3.98,5.58)$ & $4.46(3.90,5.37)$ \\
\hline FEV1 [l/s] & $3.8(3.34,4.33)$ & $3.57(3.01,4.11)$ \\
\hline Sniff PmaxPeak [kPa] & $6.24(4.84,7.67)$ & $6.25(5.09,8.63)$ \\
\hline
\end{tabular}

Compared to the initial value collected from baseline spirometry, the second spirometry showed a significant decrease of $\mathrm{VC}, \mathrm{FEV}_{1}$ and Sniff $\mathrm{P}_{\text {maxPeak }}$ in both approaches indicating phrenic nerve blocks (Table 2). Neither a difference in the spirometric parameter development from $T_{0}$ to $T_{30}$ nor a difference in the incidence of hemidiaphragmatic paresis could be observed between the anterior and the posterior approach groups (Table 3, Fig. 3). The sensitivity analysis revealed no difference between the puncture approaches at the two time points (Table 3 )

When skin suturing was started, the sedation was terminated. Upon arrival in the recovery room, 80 patients (95.2 \%; 95 \% CI: 90.7-99.8\%) already had an Aldrete score of ten; three patients (3.6 \%; $95 \%$ CI: 0.0-7.5\%) had a score of nine, and one patient $(1.2 \%$; $95 \%$ CI: $0.0-3.5 \%$ ) had a score of eight. A subjective dyspnea did not occur in any of these patients.

\section{Discussion}

As assessed by spirometry there was no difference with regards to phrenic nerve block between the anterior or posterior interscalene approach using a total of $15 \mathrm{ml}$ ropivacaine $1 \%$ for each ultrasound guided block. Despite the fact that our sample size calculation was based on a power of $80 \%$ we do not believe we have missed any relevant effect of the two different approaches in this setting because we decided to include additional patients to adress a potential drop out-rate and to give the trial more power. More details were given in the method section.

Another explanation for the absence of significance is that the volume used seems too large not to spread towards the phrenic nerve. Subsequently, the anterior or posterior site of injection cannot reduce the incidence of unintentional hemidiaphragmatic paresis in this setting.

In order to avoid phrenic nerve blocks, a reduction of the local anesthetic volume comes into consideration. Both in medical journals and in clinical practice you will find data regarding injection volumes between 20 and $50 \mathrm{ml}[12,13]$, which are higher than the $15 \mathrm{ml}$ used in this study. Meanwhile, several studies have shown that the minimum effective anesthetic volume (MEAV) for a sufficient interscalene plexus block is far below the current clinical volumes. McNaught et al. reported an MEAV of $0.9 \mathrm{ml}$ [14]. However, the operations were performed under general anesthesia, and the outcome of an effective block was postoperative analgesia $30 \mathrm{~min}$ after the end of surgery. Falcao et al. reported a similar MEAV of $0.95 \mathrm{ml}$. After having performed a preoperative sensory and motor evaluation on the block, a general anesthesia was also performed [15]. The results of a dose-finding study by Gautier et al. appear to have pioneered the interscalene plexus block and the subsequent 
Table 2 Results of the spirometry outcomes for the anterior and posterior puncture approach comparing baseline $\left(T_{0}\right)$ and 30 min after the interscalene block $\left(T_{30}\right)$

\begin{tabular}{|c|c|c|c|c|c|c|c|}
\hline \multirow[b]{2}{*}{ Spirometry variable } & \multirow[b]{2}{*}{ Time } & \multicolumn{3}{|c|}{ Anterior puncture approach } & \multicolumn{3}{|c|}{ Posterior puncture approach } \\
\hline & & $\begin{array}{l}\text { Median } \\
(\mathrm{Q} 1, \mathrm{Q} 3)\end{array}$ & $\begin{array}{l}\text { Median difference } \\
(95 \% \text { To-тзо } \\
\text { (9) }\end{array}$ & $\begin{array}{l}p \text {-value } \\
\text { (two-sided) }\end{array}$ & $\begin{array}{l}\text { Median } \\
(\mathrm{Q} 1, \mathrm{Q} 3)\end{array}$ & $\begin{array}{l}\text { Median difference } \text { то-тзо } \\
(95 \% \mathrm{Cl})\end{array}$ & $\begin{array}{l}\text { p-value } \\
\text { (two-sided) }\end{array}$ \\
\hline \multirow[t]{2}{*}{ VC [l] } & $\mathrm{T}_{0}$ & $5.09(3.98,5.58)$ & $0.95(0.79,1.11)$ & $<0.001$ & $4.46(3.90,5.37)$ & $0.96(0.81,1.14)$ & $<0.001$ \\
\hline & $T_{30}$ & $3.98(3.31,4.67)$ & & & $3.46(2.90,4.34)$ & & \\
\hline \multirow[t]{2}{*}{$\mathrm{FEV}_{1}[\mathrm{l} / \mathrm{s}]$} & $\mathrm{T}_{0}$ & $3.8(3.34,4.33)$ & $0.75(0.63,0.87)$ & $<0.001$ & $3.57(3.01,4.11)$ & $0.83(0.70,0.99)$ & $<0.001$ \\
\hline & $\mathrm{T}_{30}$ & $3.05(2.41,3.44)$ & & & $2.58(2.05,3.22)$ & & \\
\hline \multirow[t]{2}{*}{ Sniff PmaxPeak [kPa] } & $\mathrm{T}_{0}$ & $6.24(4.84,7.67)$ & $1.10(0.71,1.56)$ & $<0.001$ & $6.25(5.09,8.63)$ & $1.07(0.46,1.74)$ & $<0.001$ \\
\hline & $T_{30}$ & $5.13(4.21,7.22)$ & & & $5.70(4.54,6.83)$ & & \\
\hline
\end{tabular}

operation using $5 \mathrm{ml}$ ropivacaine $0.75 \%$ (ca. $1.7 \mathrm{ml}$ per root) without general anesthesia [16]. The minimum effective volumes for ultrasound guided interscalene blocks associated with a general anesthesia, which were reported by McNaught and Falcao [14, 15], reveal that the volume of $15 \mathrm{ml}$ used in our study was far beyond the dose required. These results had not yet been published at the time of planning for the present study (2011).

As already shown by Gautier et al. [16], the injection volume can certainly be considerably reduced in an interscalene block with sedation and without general anesthesia for shoulder operations. It would be useful to keep a concentration of $1 \%$ because probably the volume, not the administered concentration of the local anesthetic, causes problems. In 2009 Renes at al. described that the usage of an ultrasound guided supraclavicular brachial plexus block results in an up to $100 \%$ avoidance of an undesirable hemidiaphragmatic paresis $(n=30)$ [6]. However, the block was exclusively used in elbow, forearm, wrist, and hand surgery. Case studies by Erickson and Chaudhuri et al. report that also here hemidiaphragmatic paresis cannot always be avoided $[17,18]$. Erickson published a surgical study, however, without any detailed data concerning the anesthesiologic technique or the injected volume. The second case study reports an injection of $20 \mathrm{ml}$ [17].

In our study, an injection site located more distally towards the supraclavicular region could also be considered for shoulder operations in ultrasound guided brachial plexus block and sedation, in addition to the previously discussed reduction of the injection volume. In a "deep interscalene" or rather "supra-supraclavicular" position, the same parts of the brachial plexus are accessible as in an interscalene position. Particularly the suprascapular nerve and the dorsal scapular nerve are still accessible here, whereas the phrenic nerve takes a course in much larger distance. The route relating to $\mathrm{C}_{5}$ and the anterior scalene muscle can be displayed well sonographically [19]. Therefore it is postulated that the paresis rate can be effectively reduced by the up to now unusual injection site and also by the reduction of the injection volume. Verelst et al. suggested a similar strategy in 2013 [20]. This approach gains relevance from a study by Kaufman et al. [21], who described a case series of direct phrenic nerve injuries following interscalene blocks [21, 22].

Table 3 Results of the spirometry outcomes at baseline $\left(T_{0}\right)$ and 30 min after the interscalene block $\left(T_{30}\right)$ comparing the anterior and the posterior puncture approaches

\begin{tabular}{|c|c|c|c|c|c|c|c|}
\hline \multirow{2}{*}{$\begin{array}{l}\text { Spirometry } \\
\text { variable }\end{array}$} & \multirow{2}{*}{$\begin{array}{l}\text { Puncture } \\
\text { approach }\end{array}$} & \multicolumn{3}{|l|}{$\mathrm{T}_{0}$} & \multicolumn{3}{|l|}{$T_{30}$} \\
\hline & & $\begin{array}{l}\text { Median } \\
\text { (Q1, Q3) }\end{array}$ & $\begin{array}{l}\text { Median difference anterior-posterior } \\
(95 \% \mathrm{Cl})\end{array}$ & $\begin{array}{l}p \text {-value } \\
\text { (two-sided) }\end{array}$ & $\begin{array}{l}\text { Median } \\
\text { (Q1, Q3) }\end{array}$ & $\begin{array}{l}\text { Median difference anterior-posterior } \\
(95 \% \mathrm{Cl})\end{array}$ & $\begin{array}{l}p \text {-value } \\
\text { (two-sided) }\end{array}$ \\
\hline \multirow[t]{2}{*}{$\mathrm{VC}[1]$} & anterior & $\begin{array}{l}5.09 \\
(3.98,5.58)\end{array}$ & $0.38(-0.15,0.88)$ & 0.167 & $\begin{array}{l}3.98 \\
(3.31,4.67)\end{array}$ & $0.40(-0.08,0.88)$ & 0.088 \\
\hline & posterior & $\begin{array}{l}4.46 \\
(3.90,5.37)\end{array}$ & & & $\begin{array}{l}3.46 \\
(2.90,4.34)\end{array}$ & & \\
\hline \multirow[t]{2}{*}{ FEV1 [l/s] } & anterior & $\begin{array}{l}3.80 \\
(3.34,4.33)\end{array}$ & $0.25(-0.16,0.63)$ & 0.174 & $\begin{array}{l}3.05 \\
(2.41,3.44)\end{array}$ & $0.34(-0.09,0.72)$ & 0.103 \\
\hline & posterior & $\begin{array}{l}3.57 \\
(3.01,4.11)\end{array}$ & & & $\begin{array}{l}2.58 \\
(2.05,3.22)\end{array}$ & & \\
\hline \multirow[t]{2}{*}{$\begin{array}{l}\text { Sniff PmaxPeak } \\
{[\mathrm{kPa}]}\end{array}$} & anterior & $\begin{array}{l}6.24 \\
(4.84,7.67)\end{array}$ & $-0.24(-1.24,0.83)$ & 0.655 & $\begin{array}{l}5.13 \\
(4.21,7.22)\end{array}$ & $-0.23(-1.04,0.56)$ & 0.582 \\
\hline & posterior & $\begin{array}{l}6.25 \\
(5.09,8.63)\end{array}$ & & & $\begin{array}{l}5.70 \\
(4.54,6.83)\end{array}$ & & \\
\hline
\end{tabular}




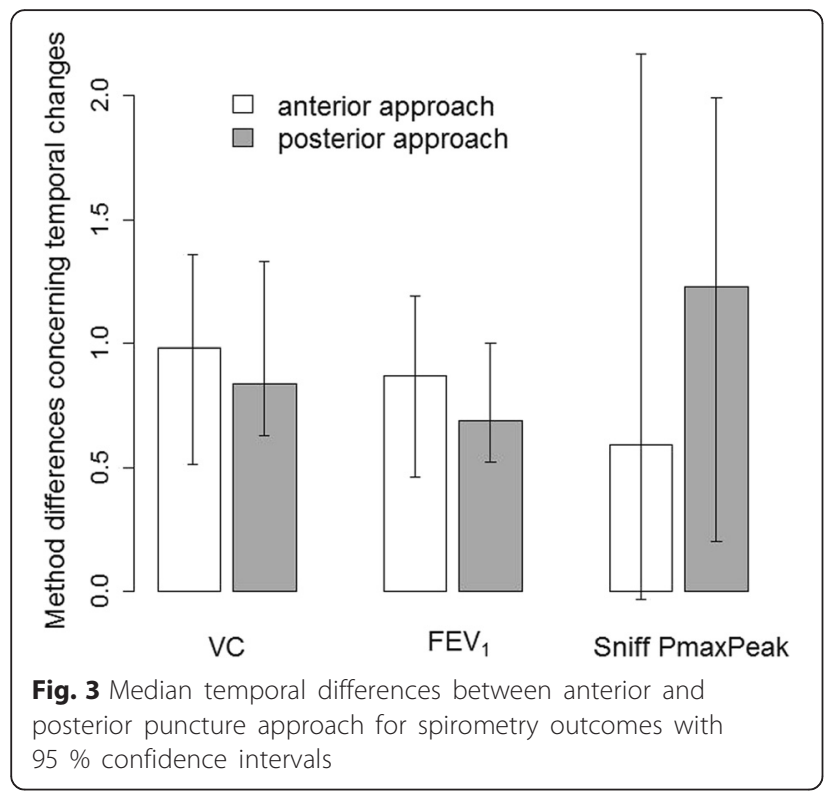

In our study, the block success rate of $98.8 \%$ is very high and is in the same range as in data published by Bishop et al. in 2005 where it is $97 \%$ [23]. There, neither the injection site nor the approach plays a role. As Lang et al. demonstrated in 2012, there is no discrepancy in the effect of the block whether the nerve roots are only partially or entirely flushed with the local anesthetic [24]. Spence et al. [25] reached a similar conclusion when they showed that an exact injection site of the local anesthetic does not make any difference regarding the effect of the block.

Despite a significant deterioration of the pulmonary function, the operation could be performed on $98.8 \%$ of our patients without general anesthesia. Likewise the monitoring in the recovery room and the postoperative course within the first $24 \mathrm{~h}$ after the block proved uneventful from a clinical point of view. This supports the clinical experience that although a hemidiaphragmatic paresis frequently occurs, it is not clinically relevant in the majority of cases in patients with normal pulmonary mechanics. Against the background of the study results, it can be assumed that $\leq$ ASA II patients without preexisting pulmonary disease are not clinically impaired by an interscalene block-induced phrenic nerve block with subsequent hemidiaphragmatic paresis. Despite the paresis, they can be moved directly from the operating room to the general patient care unit, provided that they have an Aldrete score of ten upon leaving the operating room.

However, our study has several limitations including a relatively small sample size and perhaps too large volume of local anesthetic. Furthermore, the spirometric outcomes are dependent on both the patient's cooperation and the examiner's instructions. In addition, a learning effect in patients cannot be excluded between the first and the second spirometry. This might have influenced the accuracy of diagnosing hemidiaphragmatic paresis.

From a sensitivity and specificity viewpoint, magnetic stimulation on the phrenic nerve is considered the gold standard for the diagnosis of diaphragmatic paresis. However, this procedure can only be carried out under study conditions in a few clinical centers because it is a technical and highly invasive specialized procedure, due to the placement of an esophageal pressure tube. From an ethical point of view, radiation exposure induced by a radiological examination of the diaphragm was not considered reasonable for the patients in this study.

\section{Conclusion}

We found the ultrasound guided anterior approach of the interscalene block to be equally effective to the posterior approach when an injection volume of $15 \mathrm{ml}$ ropivacaine $1 \%$ was used. There was no difference in the incidence of hemidiaphragmatic paresis. Clinical breathing effects of phrenic nerve blocks are, however, usually well compensated, and subjective dyspnea did not occur in our patients. Future studies could be aimed at a further reduction of the injected local anesthetic volume in order to reduce the incidences of hemidiaphragmatic paresis.

\section{Abbreviations}

ASA, American Society of Anesthesiologist physical status classification system; FEV 1 , forced expiratory volume per second; GOLD, Global initiative for chronic Obstructive Lung Disease; ISB, interscalene brachial plexus block; Sniff, maximum nasal inspiratory breathing maneuver; VC, vital capacity

\section{Acknowledgement}

We acknowledge support by the Open Access Publication Funds of the Ruhr-Universität Bochum.

\section{Funding}

Not applicable.

\section{Availability of data and materials}

The data will not be made available in order to protect the participants' identity

\section{Authors' contributions}

Design of study: TN, RE. Conduct of study: TN, RE, WA. Data analysis: LB, MK, TN, MA, RE. Manuscript preparation: LB, SM, MK, TN, WA, RE. All authors contributed to the development of interim and final drafts, and read and approved the final manuscript.

\section{Competing interests}

MK was supported by the Federal Ministry of Education and Research (BMBF), Germany, FKZ: 01EO1002, but received no direct funding for this work. The other authors report no competing interests.

\section{Consent for publication}

Not applicable.

\section{Ethics approval and consent to participate}

This study was conducted in accordance with the ethical principles of the Helsinki Declaration, and was approved by the Ethics Committe oft he Eberhard Karls University in Tuebingen (Germany) (Research Ethics Committee No. 579/2010B01. All patients provided prior written informed consent. 


\section{Author details}

'Klinik für Anästhesiologie, Intensivmedizin und Schmerztherapie, Knappschaftskrankenhaus Bochum Langendreer, Ruhr-Universität Bochum, In der Schornau 23-25, 44892 Bochum, Germany. ${ }^{2}$ Clinical Epidemiology, Integrated Research and Treatment Center - Center for Sepsis Control and Care (CSCC), Jena University Hospital, Jena, Germany. ${ }^{3}$ Klinik für Anästhesiologie, Intensivmedizin und Schmerztherapie, Evangelisches Krankenhaus Unna, Unna, Germany. ${ }^{4}$ Abteilung für Anästhesiologie, Intensivmedizin und Schmerztherapie, Berufsgenossenschaftliche Unfallklinik Tübingen, Tübingen, Germany.

Received: 9 March 2016 Accepted: 21 July 2016

Published online: 29 July 2016

\section{References}

1. Marhofer P, Harrop-Griffiths W, Willschke H, Kirchmair L. Fifteen years of ultrasound guidance in regional anaesthesia: part 2-recent developments in block techniques. Br J Anaesth. 2010;104:673-83.

2. Koscielniak-Nielsen ZJ. Ultrasound-guided peripheral nerve blocks: what are the benefits? Anaesthesiol Scand. 2008;52:727-37.

3. McCartney CJ, Lin L, Shastri U. Evidence basis for the use of ultrasound for upper-extremity blocks. Reg Anesth Pain Med. 2010;35:S10-5.

4. Urmey WF, Talts KH, Sharrock NE. One hundred percent incidence of hemidiaphragmatic paresis associated with interscalene brachial plexus anesthesia as diagnosed by ultrasonography. Anesth Analg. 1991:72:498-503.

5. Sala-Blanch X, Lazaro JR, Correa J, Gomez-Fernandez M. Phrenic nerve block caused by interscalene brachial plexus block: effects of digital pressure and a low volume of local anesthetic. Reg Anesth Pain Med. 1999;24:231-5.

6. Renes SH, Spoormans HH, Gielen MJ, Rettig HC, van Geffen GJ. Hemidiaphragmatic paresis can be avoided in ultrasound-guided supraclavicular brachial plexus block. Reg Anesth Pain Med. 2009;34:595-9.

7. Neal JM, Gerancher JC, Hebl JR, et al. Upper extremity regional anesthesia: essentials of our current understanding, 2008. Reg Anesth Pain Med. 2009;34:134-70.

8. Winnie AP. Interscalene brachial plexus block. Anesth Analg. 1970;49:455-66.

9. Urmey WF, McDonald M. Hemidiaphragmatic paresis during interscalene brachial plexus block: effects on pulmonary function and chest wall mechanics. Anesth Analg. 1992;74:352-7.

10. Lee JH, Cho SH, Kim SH, et al. Ropivacaine for ultrasound-guided interscalene block: $5 \mathrm{ml}$ provides similar analgesia but less phrenic nerve paralysis than $10 \mathrm{ml}$. Can J Anaesth. 2011:58:1001-6.

11. Jorgen V, Suzanne SH, Alvar GA, Paul WJ, Claus V, Antonio A, Peter JB, Leonardo MF, Fernando JM, Masaharu N, Robert AS, Don DS, Roberto RR. Global strategy for the diagnosis, management, and prevention of chronic obstructive pulmonary disease: GOLD executive summary. Am J Respir Crit Care Med. 2013;187:347-65.

12. Halaszynski TM. Ultrasound brachial plexus anesthesia and analgesia for upper extremity surgery: essentials of our current understanding, 2011. Curr Opin Anaesthesiol. 2011;24:581-91.

13. Hofmann-Kiefer K, Jacob M, Rehm M, Lang P. options and limits of interscalene nerve blocks. Anasthesiol Intensivmed Notfallmed Schmerzther. 2009:44:522-9.

14. McNaught A, Shastri U, Carmichael N, et al. Ultrasound reduces the minimum effective local anaesthetic volume compared with peripheral nerve stimulation for interscalene block. Br J Anaesth. 2011;106:124-30.

15. Falcao LF, Perez MV, de Castro I, Yamashita AM, Tardelli MA, Amaral JL. Minimum effective volume of $0.5 \%$ bupivacaine with epinephrine in ultrasound-guided interscalene brachial plexus block. $\mathrm{Br} J$ Anaesth. 2013;110:450-5.

16. Gautier P, Vandepitte C, Ramquet C, DeCoopman M, Xu D, Hadzic A. The minimum effective anesthetic volume of $0.75 \%$ ropivacaine in ultrasound-guided interscalene brachial plexus block. Anesth Analg. 2011;113:951-5

17. Erickson JM, Louis DS, Naughton NN. Symptomatic phrenic nerve palsy after supraclavicular block in an obese man. Orthopedics. 2009;32:368.

18. Chaudhuri S, Gopalkrishna M, Paul C, Kundu R. Can bilateral bronchospasm be a sign of unilateral phrenic nerve palsy after supraclavicular brachial plexus block? J Anaesthesiol Clin Pharmacol. 2012;28:249-51.
19. Kessler J, Schafhalter-Zoppoth I, Gray AT. An ultrasound study of the phrenic nerve in the posterior cervical triangle: implications for the interscalene brachial plexus block. Reg Anesth Pain Med. 2008;33:545-50.

20. Verelst $P$, van Zundert $A$. Respiratory impact of analgesic strategies for shoulder surgery. Reg Anesth Pain Med. 2013;38:50-3.

21. Kaufman MR, Elkwood Al, Rose Ml, et al. Surgical treatment of permanent diaphragm paralysis after interscalene nerve block for shoulder surgery. Anesthesiology. 2013;119:484-7.

22. Hogan QH. Phrenic nerve function after interscalene block revisited: now, the long view. Anesthesiology. 2013;119:250-2.

23. Bishop JY, Sprague M, Gelber J, et al. Interscalene regional anesthesia for shoulder surgery. J Bone Joint Surg Am. 2005;87:974-9.

24. Lang RS, Kentor ML, Vallejo M, Bigeleisen P, Wisniewski SR, Orebaugh SL. The impact of local anesthetic distribution on block onset in ultrasoundguided interscalene block. Acta Anaesthesiol Scand. 2012;56:1146-51.

25. Spence BC, Beach ML, Gallagher JD, Sites BD. Ultrasound-guided interscalene blocks: understanding where to inject the local anaesthetic. Anaesthesia. 2011;66:509-14.

\section{Submit your next manuscript to BioMed Central and we will help you at every step:}

- We accept pre-submission inquiries

- Our selector tool helps you to find the most relevant journal

- We provide round the clock customer support

- Convenient online submission

- Thorough peer review

- Inclusion in PubMed and all major indexing services

- Maximum visibility for your research

Submit your manuscript at www.biomedcentral.com/submit
Biomed Central 